This report was prepared as an account of work sponsored by an agency of the United States Government. Neither the United States Government nor any agency thereof, nor any of their employees, makes any warranty, express or implied, or assumes any legal liability or responsibility for the accuracy, completeness, or usefulness of any information, apparatus, product, or process disclosed, or represents that its use would not infringe privately owned rights. Reference herein to any specific commercial product, process, or service by trade name, trademark, manufacturer, or otherwise does not necessarily constitute or imply its endorsement, recommendation, or favoring by the United States Government or any agency thereof. The views and opinions of authors expressed herein do not necessarily state or reflect those of the United States Government or any agency thereof.

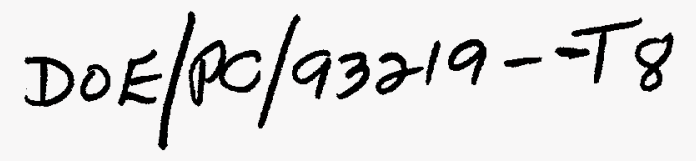

\title{
Novel Carbon-Ion Fuel Cells
}

Quarterly Technical Report

Performance Period 9/1/93 - 03/31/96 (Quarter \#10)

\author{
Submitted to the \\ U.S. Department of Energy
}

Grant Number DE-FG22-93PC93219

Grant Period 10/1/93 to $9 / 30 / 96$

\author{
Principal Investigator \\ F. Hadley Cocks
}

Chairman, Department of Mechanical Engineering \& Material Science

Duke University

DOE Technical Project Officer

Kamalendu Das

Morgantown Energy Technology Center

"U.S. DOE Patent Clearance is not required prior to the publication of this Document"

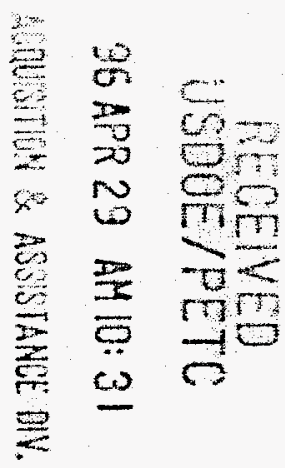




\section{DISCLAIMER}

Portions of this document may be illegible in electronic image products. Images are produced from the best available original document. 


\section{TASK DESCRIPTION}

This report presents research to develop an entirely new, fundamentally different class of fuel cell using a solid electrolyte that transports carbon ions. This new class of fuel cell would use solid carbon dissolved in molten metal as a fuel reservoir and anode. Expensive gaseous or liquid fuel would not be required.

A high temperature fuel cell based on a carbon ion membrane/electrolyte would operate in a manner reminiscent of yttria-doped zirconia solid oxide fuel cells. Unlike zirconia, which transports oxygen ions from the atmosphere to the gas to be oxidized, however, the carbon ion electrolyte fuel cell would transport the carbon in ionic from a fuel source to the oxygen gas present in the atmosphere. Such carbon-ion fuel cells, operating at temperatures above $1000 \mathrm{C}$, would produce an exhaust gas that could be fed directly into existing boilers, and could thus act as "topping cycles" to existing power plant steam cycles.

Fuel cell technology has progressed from laboratory study in England during the period 1804-1960 to space applications in the USA from 1957-1975. With current technology, four classes of cells predominate: hydrogen ion electrolyte cells, phosphoric acid electrolyte cells, molten carbonate electrolyte cells, and solid oxide electrolyte cells. Hydrogen ion cells have advanced to the point that they are the best power technology for many space applications. The other three classes of cells are at the age when demonstration plants of up to 5 megawatt are being built. 1 All four fuel cell types use gaseous fuels: hydrogen, carbon monoxide or $\mathrm{H} 2$ and $\mathrm{CO}$ derived from methane. No fuel cell that uses a solid fuel has advanced beyond laboratory study, despite the fact that the majority of the world's fossil fuel reserves are solid carbon in the form of coal.

After identification by Japan's Ministry of International Trade and Industry (MITI) as a technology in which to strive for international industrial superiority, the Japanese are currently the world's largest supporters of fuel cell research, and have committed Japan to establishing 2000 
megawatts of fuel cell capacity by the year 2000 at an estimated cost of 3 billion US dollars. ${ }^{2}$ By the year 2010 Japan intends to have 8300 megawatts installed. 2

Fuel cell development is being funded in the USA at one seventh the Japanese rate and in Europe at one tenth the Japanese rate. 1,3,4 A World Fuel Cell Council was launched in September 1991 to coordinate fuel cell technology ${ }^{2}$ These commitments indicate that these four classes of fuel cells are near commercial viability after decades of research funding.

Thermodynamic factors favor a carbon-ion fuel cell over other fuel cell designs. A combination of enthalpy, entropy and Gibbs free energy values makes the reaction of solid carbon and oxygen one of remarkable high efficiency. The entropy change in the reaction allows this efficiency to slightly increase at high temperatures, unlike gas-fed fuel cell designs that decrease in efficiency with temperature. ${ }^{5}$ In addition to its potential for high efficiency in a single step of energy to electricity conversion inside the fuel cell, the high temperature exhaust of the carbon-ion fuel cell could make the cell useful as a "topping cycle," to be followed by conventional steam turbine systems. This two step system could be economically viable at cell efficiencies as low as $15 \% .6$

High temperature operation can be seen to have dual advantages. First, solid electrolytes inherently reach higher levels of ionic conductivity as the temperature increases to just below their melting point. Second, elevated operation allows the exhaust gas of the carbon-ion fuel cell to exit with enough temperature to feed a "bottoming Carnot cycle" placed downstream of the fuel cell so that total combined efficiency of the fuel cell/turbine combination is increased. Only highly refractory materials like the rare-earth carbides have melting temperatures that allow operation at these elevated levels.

Carbon ions are known to exist in select compounds. Wells, in his classic text $\underline{\text { Structural }}$ Inorganic Chemistry, divides the nature of carbides into Classes 1,2,3, and 4.7 Class 1 are the carbides of the more electropositive elements that have many of the properties associated with ionic crystals: such as colorless transparent crystals and electronic insulation. Wells further sub-divides Class 1 carbides into Group A and Group B. Group A, Class 1 carbides yield methane upon 
hydrolysis with water. 8 Beryllium carbide and aluminum carbides are in this group and class. Group B, Class 1 carbides yield acetylene upon hydrolysis with water, and contain the well known calcium carbide along with $\mathrm{SrC}_{2}$ and $\mathrm{BaC}_{2}$. Group $\mathrm{B}$ Class 1 carbides are thought to contain C-C -2 ions that are cigar like in shape. 9

Class 2 carbides are those from the elements from $\mathrm{La}$ to $\mathrm{Lu}$. Class 2 carbides form three types of crystal structures, some of which are similar to those of Class 1, but Class 2 carbides have mixed and varying characteristics that are temperature dependent. 10 For example, room temperature hydrolysis with water of $\mathrm{LaC}_{2}$ or $\mathrm{CeC}_{2}$ yield a mixture of acetylene, methane and other hydrocarbons, but when the temperature is increased to 200 Centigrade, no acetylene is produced and the product is primarily methane.

The crystal structures of many carbides may be favorable for good ionic conduction. Compounds with atomic crystal structures analogous to the known ionic conductor calcium fluorite exist in the carbides but have not been studied as electrolytes, probably due to a traditional assumption that carbon forms only covalent bonds without any exceptions. $12,13,14$

The economic consequences of a carbon-ion fuel cell would be extremely valuable, particularly in the USA with its large reserves of coal. A carbon-ion fuel cell could be fueled directly from either solid un-gasified coal, coke, or petroleum coke.

The environmental benefits of a carbon-ion fuel cell would be substantial. With the electrolyte in the cell inherently designed for passing only carbon-ions, emissions from the cell of $\mathrm{SO}_{2}, \mathrm{NO}_{\mathrm{x}}$ and particulates would be near zero. Conventional solid oxide fuel cells pass oxygen ions and can form these unwanted pollutants. As the anode of a carbon-ion fuel cell would consist of a molten metal such as iron, impurities in the solid fuel fed to the cell could be trapped in slag formed in the molten metal in a manner similar to those employed in steel furnaces. This slagging prior to reaction is a feature unique to the carbon-ion fuel cell design and is somewhat analogous to the advantage fluidized bed combustion with limestone has over conventional combustion.

With this overview, we now discuss the thermodynamics of such carbon-ion fuel cells. 


\section{A Review of Carbon-Ion Fuel Cell Thermodynamic Efficiency}

It has long been recognized that producing electricity chemically in fuel cells has thermodynamic advantages over producing electricity with the cycles traditionally used that rely on combustion-working fluid-turbine-generator combinations. To contrast the fuel cell to these cycle combinations, the first step is the familiar Carnot equation which limits conventional power cycles to a maximum permitted efficiency of $\left(\mathrm{T}_{2}-\mathrm{T}_{1}\right) / \mathrm{T}_{2}$, where $\mathrm{T}_{1}$ is the low temperature reservoir ( air or water outside the plant ) into which the plant exhausts it's heat, and $T_{2}$ the high temperature reservoir (a working fluid heated by fuel combustion) from which the turbine obtains energy. In the best modern power plants $T_{1}$ is typically 311 Kelvin ( 100 Fahrenheit) and $T_{2}$ is $922 \mathrm{~K}$ (1200 Fahrenheit). ${ }^{4}$ The maximum theoretical efficiency is therefore about $66 \%$. In reality, heat losses, friction and pollution controls reduce this maximum permitted efficiency to an actual efficiency of approximately $39 \%$ in today's best coal fired plants. Incremental improvements may increase this to $45 \%$ in a decade. ${ }^{15}$

The theoretical maximum efficiency of a fuel cell is given by $\Delta \mathrm{G} / \Delta \mathrm{H}$, where $\Delta \mathrm{G}$ is the change in Gibbs free energy of the chemical reaction in the cell, and $\Delta \mathrm{H}$ is the change in enthalpy of the chemical reaction in the cell. ${ }^{4}$ Table 1 is a compilation of chemical reactions listing the appropriate values of $\Delta \mathrm{H}$ and $\Delta \mathrm{G}$ for Standard Conditions of 298 degrees Kelvin and one atmosphere of pressure, plus the maximum efficiencies of fuel cell operation at 298,600 and 1000 K. 4

\section{TABLE 1}

Fuel Cell Thermodynamic Values and

Maximum Permitted Efficiencies 4

$\begin{array}{llllll}\text { Reaction } & \Delta \mathrm{H} 298 & \Delta \mathrm{G} 298 & \% \mathrm{E} @ 298 \mathrm{~K} & \% \mathrm{E} @ 600 \mathrm{~K} & \% \mathrm{E} @ 1000 \mathrm{~K} \\ \mathrm{H}_{2}+1 / 2 \mathrm{O}_{2}=\mathrm{H}_{2} \mathrm{O}(\mathrm{liq}) & 286.0 & 237.3 & 82.97 & \text { n.a. } & \text { n.a. } \\ \mathrm{H}_{2}+1 / 2 \mathrm{O}_{2}=\mathrm{H}_{2} \mathrm{O}(\mathrm{g}) & 253 & 237.3 & 94.01 & 87.93 & 79.90 \\ \mathrm{CO}+1 / 2 \mathrm{O}_{2}=\mathrm{CO}_{2}(\mathrm{~g}) & 283.1 & 257.2 & 90.86 & 81.60 & 69.33 \\ \mathrm{C}+\mathrm{O}_{2}=\mathrm{CO}_{2}(\mathrm{~g}) & 393.7 & 394.6 & 100.22 & 100.44 & 100.73\end{array}$


Note that the oxidation of solid carbon has the surprising efficiency of $100.22 \%$ at 298 Kelvin (77 Fahrenheit) and $100.73 \%$ at 1000 Kelvin (1340 Fahrenheit). This is not a misprint, but is also NOT a violation of the First or Second Law of Thermodynamics. As explained by Appleby in Fuel Cell Handbook, "It is interesting to note that for combustion reactions which proceed with an increase in entropy, energy conversion efficiencies in excess of $100 \%$ are theoretically possible. In addition to converting the chemical energy contained in the reactants to free energy in the form of electricity, such reactions theoretically would absorb additional heat from the surroundings and convert this heat to additional electrical energy so long as the heat could be supplied." 4

In other words, the small amount of efficiency over $100 \%$ is not coming directly from inside the fuel cell but is the result of heat transferred from the environment that surrounds the fuel cell system. This heat transfer is due to entropy change between reactants and products in solid carbon oxidation.

One should not dwell upon this high numerical value as extraordinary, except to point out that a carbon-ion fuel cell that was only "utilizing" $33 \%$ of its theoretical maximum potential at a practical operating temperature of 1000 Kelvin would still be $33 \%$ efficient, whereas a hydrogen / oxygen fuel cell operating at 1000 Kelvin would only be $.33 \times 79.9 \%=26 \%$ efficient. (refer back to Table 1, column of values @ 1000K) Even more disadvantaged would be a carbon monoxide/oxygen fuel cell where the efficiency would drop to $.33 \times 69.33 \%=23 \%$.

If one were given a supply of carbon as a base stock to run a fuel cell, it is today possible to react the carbon with steam in the "water gas" reaction and run an "off the shelf" fuel cell on the resultant hydrogen and carbon monoxide. However, the above numbers indicate that it would be far more thermodynamically efficient to have a carbon-ion fuel cell to directly consume the solid carbon.

Mathematically, this relationship between entropy and thermodynamic efficiency can be expressed as follows:

Maximum Efficiency $=[\Delta G / \Delta H] \times 100 \%$

Substitute in the above equation: 
$\Delta \mathrm{G}=\Delta \mathrm{H}-\mathrm{T} \Delta \mathrm{S}$ where $\Delta \mathrm{S}$ is the change in entropy

and $\mathrm{T}$ is Temperature in Kelvin.

Maximum Efficiency $=(\Delta \mathrm{H}-\mathrm{T} \Delta \mathrm{S}) / \Delta \mathrm{H} \times 100 \%$

Rearranging the above terms:

$$
=[1-(\mathrm{T} \Delta \mathrm{S} / \Delta \mathrm{H})] \times 100 \%
$$

If the number $(\mathrm{T} \Delta \mathrm{S} / \Delta \mathrm{H})$ is a negative number, then the maximum efficiency can be greater than $100 \%$ because the environment around the fuel cell is transferring energy into the fuel cell in an amount equal to T $\Delta \mathrm{S}$.

A carbon-ion fuel cell would operate at a temperature above the melting point of the metal used as the anode of the cell. At a temperature of 1500 Celsius (2732 Fahrenheit) the nominal melting point of iron, the maximum efficiency of the reaction of carbon and oxygen is theoretically $101.31 \%$.

If it would be desirable to operate a carbon-ion fuel cell at a lower temperature, several lower melting point metals for use as the cell anode are available. Aluminum, Calcium and Lithium are potential candidates with melting temperatures ranging from 839 to 181 Celsius. Carbon/Lithium electrochemical cells might have great potential as primary or secondary batteries due to the energy density that is theoretically possible. By selecting different metals, the carbon-ion fuel cell concept can be designed to operate over a wide temperature range, but high temperatures are preferred for efficiency reasons.

The solid carbon reaction increases very slightly in efficiency with an increase in temperature. As can be seen from an examination of Table 1, in the other two oxidation reactions that dominate gas fuel cells, hydrogen or carbon monoxide, efficiency decreases at a significant rate with an increase in temperature. Therefore, the electrochemical oxidation of solid carbon has a theoretical efficiency advantage over the oxidation of either hydrogen or carbon monoxide of approximately $12-31 \%$ at realistic operating temperatures.

The above maximum efficiency numbers should be compared to that achieved in cells constructed using today's best techniques. For example, some hydrogen cells in the space 
program have achieved efficiencies near $60 \%$, versus their maximum of $94 \%$ as shown in the Table 1. ${ }^{4}$ Published designs for a power plant that combines a hydrogen/carbon monoxide cell using a molten carbonate electrolyte with a bottoming cycle steam turbine contain estimates of $48 \%$ efficiency for real operating conditions. 1

As shown above, the carbon oxidation reaction is less sensitive to increases in temperature. This has an important beneficial effect on the electrolyte used in the fuel cell. As the ionic conductivity of electrolytes generally increase with temperature, a benefit of this temperature tolerance should be to increase the number and types of materials having usable values of ionic conductivity. Atomic crystal structures that have had too low an ionic conductivity to be recognized as useful ionic conductors between the 100-600 C (221-1112 Fahrenheit), where previous cells have operated, have the potential for operation of a carbon-ion fuel cell at $1500 \mathrm{C}$.

A further theoretical point concerning carbon is that at a ionic valence of -4 , it has a charge carrying advantage over hydrogen whose ionic valence is +1 . When passing through a electrolyte, only $1 / 4$ the number of -4 carbon ions need to diffuse across the electrolyte to carry the same current as do +1 hydrogen ions. Compared to carbon monoxide or oxygen ions, only $1 / 2$ the number of carbon ions need to cross the electrolyte as do ions that have a valence of + or -2 .

The efficiency possible with a carbon fuel cell can lead to lower cost electricity. A second environmental point to be made is that this same intrinsic efficiency leads to less production of $\mathrm{CO}_{2}$ for each kilowatt-hour produced. While the question of $\mathrm{CO}_{2}$ emissions into the atmosphere and global warming is still very uncertain, it is prudent to investigate methods that make the best use of each molecule of $\mathrm{CO}_{2}$.

A directly analogous fuel cell could be constructed using a carbon-ion electrolyte rather than a oxygen-ion electrolyte. The carbon-ion electrolyte fuel cell would have the advantage that the carbon dioxide gas product would not be mixing with the super-heated carbon vapor used as fuel in the quartz ionization chamber. With discussion of the thermodynamics of carbon-ion fuel cells, we now review the crystallographic requirements needed by potential carbon-ion electrolyte membranes. 


\section{A Review of Electrolyte Crystal Structures}

The critical element in an investigation of carbon-ion superionic conductors is clearly first to identify and then improve solid electrolytes in which carbon ions are mobile. Any candidate carbon ion electrolyte must also have low electronic conductivity and must be inert to unwanted chemical reactions involving the other materials that would make up the fuel cell, such as: the molten metal anode, the cathode material and impurities in the fuel.

The ideal material for the transport of carbon ions must exhibit ionic conductivity's greater than approximately $0.1 \mathrm{ohm}^{-1}$ centimeter $^{-1}$ and electronic conductivity's less than $10^{-3}$ $\mathrm{ohm}^{-1}$ centimeter ${ }^{-1}$. $^{16}$ These two characteristics are tied to the crystal structure and bonding in the carbide. While past research on carbides has not explored the ionic conductivity to the extent which compounds containing oxygen, fluorine, or sodium ions have been studied, past carbide research is valuable in pointing out which carbon compounds, such as $\mathrm{SiC}$, are good electronic conductors. $\mathrm{SiC}$ is used as a heating element in many furnaces.

Zirconium Oxide $\left(\mathrm{ZrO}_{2}\right)$, has a good combination of high ionic conductivity and low electronic conductivity for application with oxygen ions. ${ }^{17} \mathrm{ZrO}_{2}$ has the same crystal structure above $2000 \mathrm{C}$ as fluorite $\left(\mathrm{CaF}_{2}\right)$ and can be "stabilized" so as to hold this crystal structure at lower temperatures by the process of controlled contamination with another element termed "doping". Figure 1.30, reproduced from Smart and Moore, shows various views of the fluorite crystal structure. 


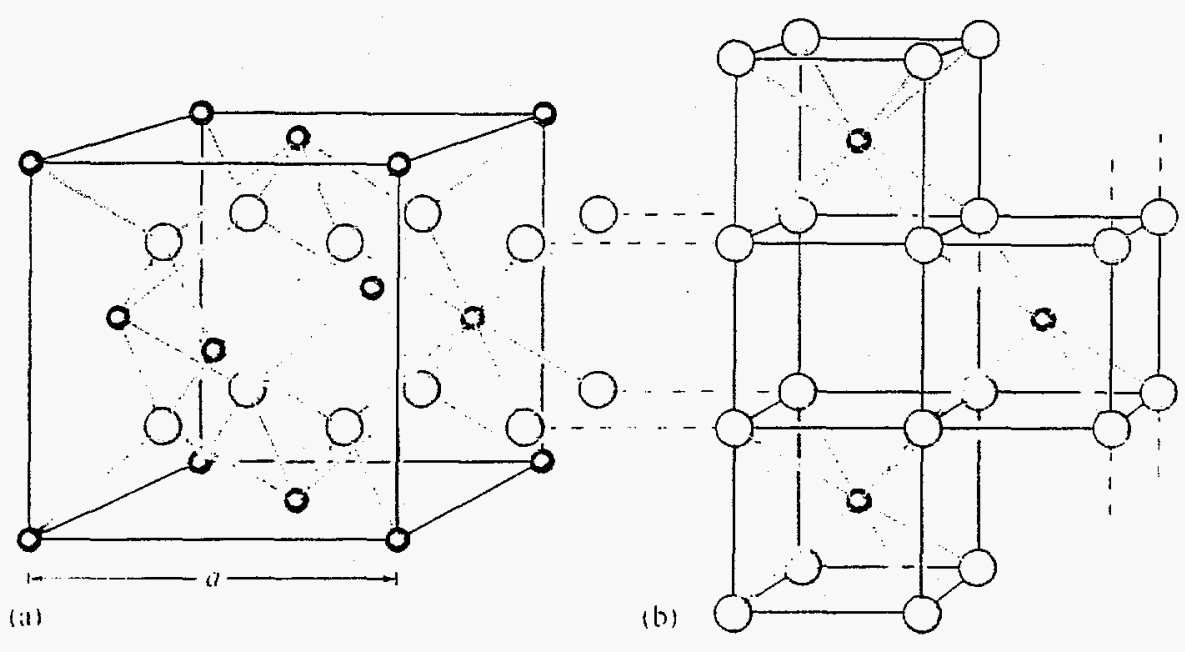

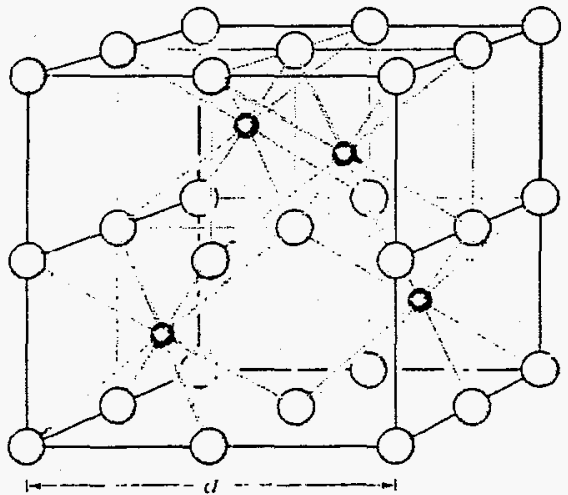

(c)

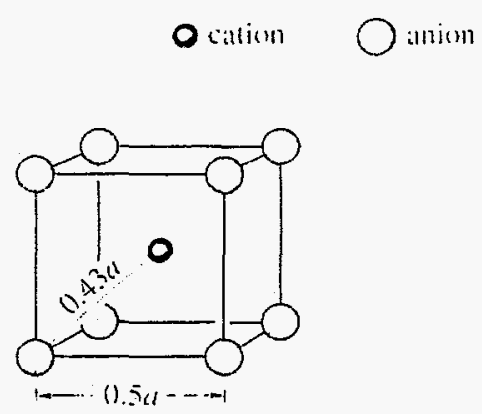

(d)

Figure 1.30) The crystal structure of thorite $\left(\mathrm{CaF}_{2}\right)$. (a) Unit cell as a cop array of cations. (b) and (c) The same structure redrawn as a primitive cubic array of anions: the unit cell is marked by a coloured outline in (c). (d) Relationship of unit cell dimensions to the primitive anion cube (the octant). 
Proper doping not only stabilizes the crystal structure but also can greatly increase the ionic conductivity by introducing vacancies in the oxygen ion lattice. Figure 1, reproduced from Steele ${ }^{18}$, illustrates the successful doping of the fluorite crystal structure compounds of oxides such as the zirconias and cerias

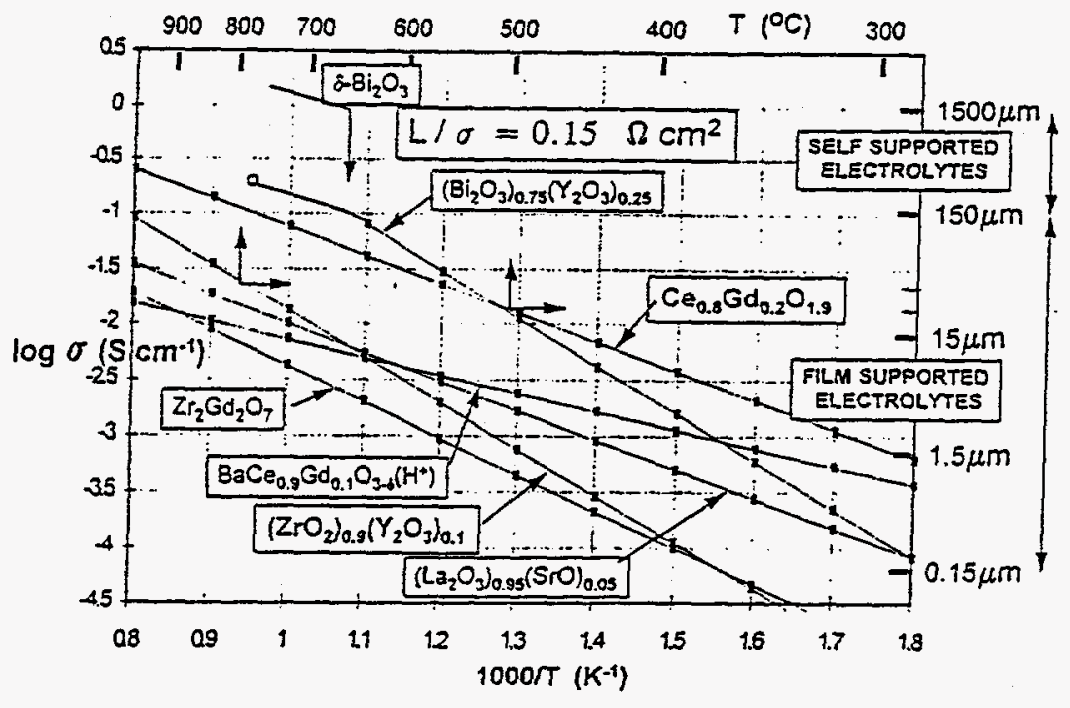

Figure 1: Specific Ionic Conductivity values for selected oxide electrolytes as a Function of Reciprocal Temperature.

Properly doped $\mathrm{ZrO}_{2}$ has been termed a "superionic" conductor. However, the use of Zirconium can not be immediately transferred to carbides. $\mathrm{ZrC}$ does not have the fluorite crystal structure. Even more troublesome is the fact that $\mathrm{ZrC}$ is a moderately good electronic conductor at $8300 \mathrm{ohm}^{-1} \mathrm{~cm}^{-1}$. $^{19}$ Electronic conductivity in a solid electrolyte would short-circuit the fuel cell or battery it was used in. Some carbides do have low electronic conductivity. $\mathrm{CaC}_{2}$ has an electronic conductivity of $0.0017 \mathrm{ohm}^{-1}$ - centimeter-1, but not the fluorite structure. 20 
Chemically, the fluorite structure has the formula $\mathrm{RX}_{2}$ where $\mathrm{R}$ is a cation and $\mathrm{X}$ is an anion and the ionic radii of $R$ is greater than 0.73 times that of the ionic radius of $X$. Table 2 lists carbides that have the fluorite crystal structure at elevated temperature. ${ }^{21}$

\section{TABLE 2}

Fluorite Structure Carbide Characteristics

COMPOUND

$\mathrm{EuC}_{2}$
$\mathrm{CeC}_{2}$
$\mathrm{LaC}_{2}$
$\mathrm{NdC}_{2}$
$\mathrm{SmC}_{2}$
$\mathrm{GdC}_{2}$
$\mathrm{TbC}_{2}$
$\mathrm{HoC}_{2}$
$\mathrm{ErC}_{2}$
$\mathrm{YC}_{2}$
$\mathrm{TmC}_{2}$
$\mathrm{LuC}_{2}$

TRANSITION TEMPERATURE alpha to beta, Celsius

$*$

*

$*$

$*$

*

$*$

*

$*$

$*$

$*$

$*$

*
350

1050

1060

1150

1170

1240

1288

1300

1310

1324

1355

1450

Loe et al 22 have shed considerable light on the fundamentals of stabilizing the beta (fluorite) crystal structure of the lanthanide carbides. Loe demonstrated a relationship, when changing from the high-temperature cubic fluorite structure to the tetragonal structure, between the transition temperature, $T_{t}$, of lanthanide dicarbide solid solutions, and the lattice strain energy, as represented by the square of the cell volume difference, $\Delta \mathrm{V}$, for $50 \%$ mole solid solutions. The following graph from Loe 22 illustrates the transition temperature depression for $50 \%$ additions of other lanthanide carbides to $\mathrm{LaC}_{2}$. Notice that the depression of transition temperature is greater than 500 degrees Centigrade for the mixture $50 \% \mathrm{LaC}_{2} / 50 \% \mathrm{GdC}_{2}$. 


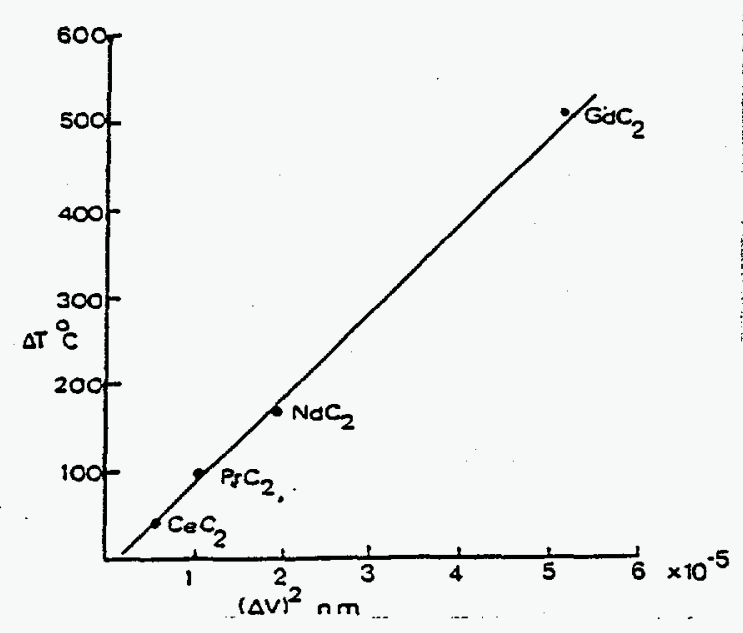

Figure 2: Depression of Solvent Transformation Temperatures when LaC2 50 mole\% is Solute Against Cell Volume Difference Squared

Loe makes the prediction that when "these strains exceed $16 \mathrm{kJoule} / \mathrm{mole}$, nucleation of the tetragonal polymorph is prevented and the cubic phase is stabilized to room temperature." 23 Stabilization to room temperature would be very desirable to prevent phase transition thermal cracking in a fuel cell electrolyte undergoing repeated large temperature variations during operation.

Sammells et al 24 have made important contributions to the basic science of systematic selection of electrolytes and dopants to improve electrolyte performance. By examining the "free volume" of the lattice structure of both perovskite and fluorite oxides, they have postulated that the activation energy for ionic conduction goes down with decreasing free volume for fluorite crystal structures. (They also postulate the opposite effect for oxides of perovskite crystal structure.) Sammells defines "free volume" as the difference between the volume of the crystallographic unit cell and the volumes occupied by the constituent ions resident at lattice sites. This relationship is illustrated in the Figure 3. 24 


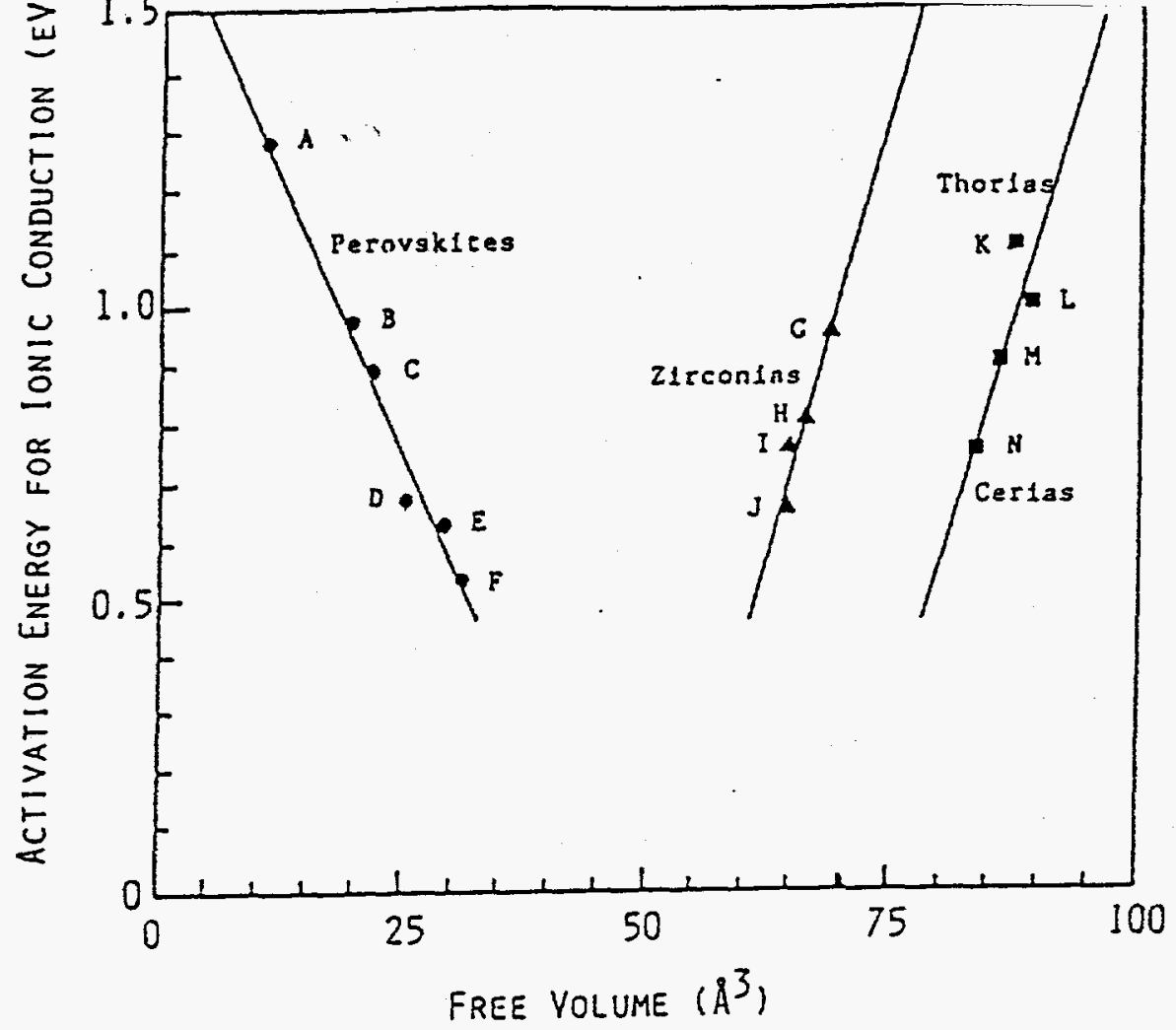

Figure 3: Correlation of Activation Energies for Anion Transport in Solid Electrolytes As a Function of Free Volume

Aluminum carbide, $\mathrm{Al}_{4} \mathrm{C}_{3}$, is also an interesting candidate for carbon-ion conduction. In aluminum carbide, carbon has two distinct positions. As stated by Wells 7 , "The structure... is rather more complex...It is sufficient to note that each carbon atom is surrounded by $\mathrm{Al}$ atoms at distances from 1.90 to 2.22 angstroms, the shortest $\mathrm{C}-\mathrm{C}$ distance being $3.16 \mathrm{~A}$. As in $\mathrm{Be}_{2} \mathrm{C}$ therefore, there are discrete $\mathrm{C}$ atoms, accounting for the hydrolysis to $\mathrm{CH}_{4}$." Figure 1.40, reproduced from Wycoff 14 is a depiction of the aluminum carbide structure. Note that the distinct carbon atoms in the center of the drawing constitute a "layer" along which anion conduction might occur.

Aluminum carbide and beryllium carbide have distinct carbon-ions in their crystal structure at room temperature. At high temperature, the lanthanide carbides have the fluorite crystal structure well known for anion conduction, and may also have distinct carbon-ions in their structure. Based on these considerations, our experimental proceedures to develop a solid carbon ion electrolyte have focused on rare earth carbides, especially cerium carbide, and the carbides of aluminum and beryllium. 
Figure 1.40: Two Projections of the elongated hexagonal Al4C3 Structure. In the upper Projection the Carbon atoms are black.

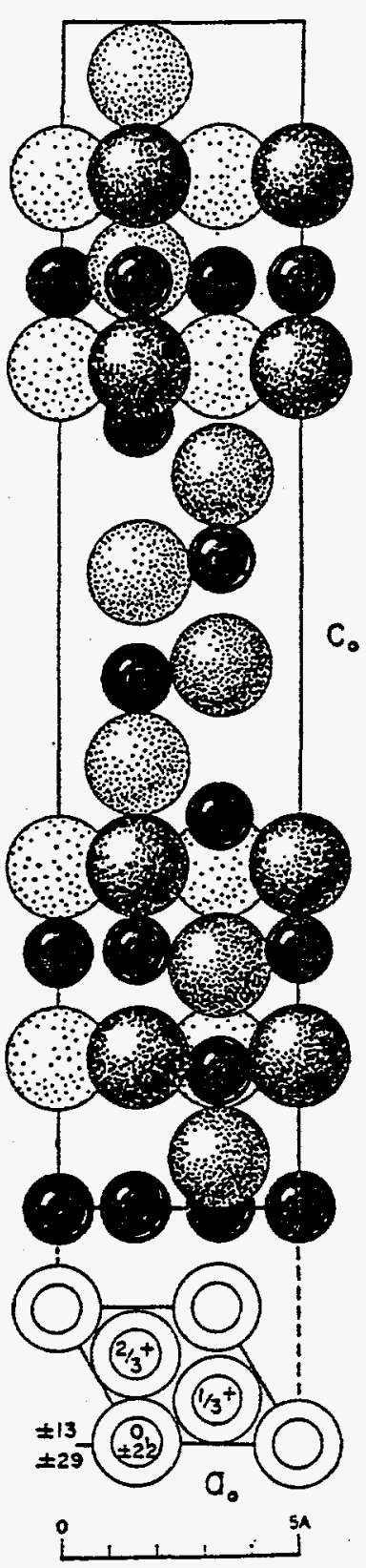




\section{Experimental Procedures}

The sequence of laboratory research procedures necessary to develop a solid carbon-ion electrolyte and to determine the ionic conductivity of carbon-ions in this electrolyte can be broken down into the following series of steps:

1. Launch an exhaustive and continuing literature search for all relevant past research on carbides, crystal structures of carbides, carbon diffusivity in carbides and basic thermodynamic qualities of carbides.

2. Procure materials and equipment for the production and analysis of carbides.

3. Perfect a method to produce a repeatable geometric shape of carbide. The carbide could conceivably be a pressed and sintered pellet, a casting from the molten state, a single crystal, or a suitably thick film. The preferred geometric shape would have the following characteristics:

a. Mathematically simple so that diffusion equations are readily applied. (Irregular shapes could be approximately solved by computer modeling, however.)

b. Flat surfaced in at least one dimension so that analysis techniques such as SIMS (Secondary Ion Mass Spectroscopy), XRD (X-Ray Powder Diffraction), and SEM (Scanning Electron Microscope) are readily applicable.

A pressed and sintered, (or hot pressed) pellet would seem to be the preferred geometry, but a cast pellet or ingot might also be acceptable if surface roughness and contamination could be controlled to acceptable limits. Casting has potential advantages in the area of introducing dopants to the carbides in a more uniform manner than pressing and 
sintering mixtures of powders.

4. Uniformly alloy the carbide with other elements, or "dopants," to

a. Stabilize the preferred crystal structure so that this phase of the carbide exists over the entire temperature range in which the carbide would be used as an electrolyte. This requirement is not theoretically necessary, but is instead a practical requirement, as phase changes in an solid electrolyte over its operating temperature range will usually result in cracking and resultant failure of the fuel cell. DTA (Differential Thermal Analysis) techniques should, in theory, be a fast and low cost method of detecting the phase transition temperatures. High Temperature X-Ray Powder Diffraction is another method to exactly quantify the transition temperature and crystal structure.

b. Decrease the electronic conductivity. This will eliminate parasitic losses in the fuel cell.

c. Decrease the "free volume" (as per Sammells). This will decrease the activation energy for ionic conduction.

d. Introduce defects in the crystal structure. This will further decrease the activation energy for ionic conduction.

5. Produce the geometric shapes from the doped carbide solid electrolytes.

6. Determine the ionic conductivity of carbon-ions in the electrolytes.

Historically, ionic conductivity measurements have been made by either of two methods: electrochemical cells or tracer diffusion. In the electrochemical cell method, generally four probes are affixed to the cell. The probes can be electronically conductive, ionically conductive, or both. 
The current and voltage applied can be either alternating current of varying frequency, or direct current. The cell is then raised to the operating temperature of interest and the current and voltage drop measured.

In tracer diffusion, the electrolyte is coated or brought into contact with an element that can be readily detected by some analytical means. The electrolyte is then annealed at the operating temperature of interest. After annealing, the electrolyte is analyzed for the amount of the tracer along its dimensions in either a continuous or sectional manner.

In this research it was originally proposed that an electrochemical cell be used to test each potential carbide electrolyte at $1500 \mathrm{C}$ using conventional four probe contact measurements and varying frequency alternating current. 25 As the research proceeded, it was determined that tracer diffusion would be a simpler, more versatile, and less costly technique.

The tracer diffusion method adopted is as follows: Coat the carbide shape on one surface with a layer of a carbon isotope suitable for use as a tracer. The carbon isotopes most used as tracers in other research efforts have been Carbon-13 and Carbon-14. Carbon-13 has the advantage that it is stable, non-radioactive and closest in mass to Carbon-12. Carbon-14 has potential advantages in that it can make use of the wide range of "radioactive carbon dating" technology that has been developed in anthropology. It obvious principle disadvantage is its radioactivity, which precludes its use in many instruments that must not be contaminated with radioactivity.

In this research Carbon-13 will be used as the tracer. Carbon-13 was selected due to its non-radioactive advantages and its closeness in mass to the natural carbon that would actually be used in fuel cell operation. In addition, many of the specific scientific instruments needed to conduct the research are located in facilities that prohibit the use of even minute amounts of radioactive materials.

7. Anneal the carbon coated electrolyte pellet in a environment controlled for temperature, atmosphere and time. The annealing process be allow the carbon isotope tracer to diffuse into the carbide to a depth that can be accurately measured. 
8. Analyze the carbon isotope content of the pellet after annealing.

If the geometry of the carbide is one of the simple shapes that allows a mathematical solution to the diffusion equations, then the diffusion co-efficient can be readily calculated. For example if a Carbon- 13 isotope coating of purity $\mathrm{C}_{\mathrm{O}}$ can be approximated as a perfect film of thickness $\mathrm{b}$ at one end of a long rod (the pellet 's length), then the final concentration of the carbon isotope at any distance $x$ along the pellet's length after an annealing time $T_{a}$ is given by the equation 26 :

Concentration $C-13(x, t)=\left[\left(b_{0}\right) / 2\left(\right.\right.$ square root $\left.\left.\left(\pi T_{a} D\right)\right)\right] \exp \left\{-x / 4 D T_{a}\right\}$

where $\mathrm{D}$ is the diffusion co-efficient of Carbon-13 in the lanthanide carbide. Once the diffusion coefficient is known, the conductivity can be found from the equation:

Conductivity $=\left[\mathrm{D} \times \mathrm{N}_{\mathrm{i}} \times \mathrm{q}^{2}\right] /[\mathrm{R} \times \mathrm{T} \times($ Molar Volume of the Carbide) $]$.

Here we also assume that the diffusion co-efficient of Carbon-12 would be similar, or of approximately the same magnitude, as that of Carbon-13.

SIMS is one method of analyzing this carbon concentration.

Another possible method would be to slice thin layers from the pellet and spectrographically analyze each layer. In this research SIMS will be the method used to determine the carbon diffusion characteristics.

Low cost carbon-13 ( $\$ 255 /$ gram ) and carbon-12 ( \$71/gram ) isotopes of 99.9\% purity have only recently become available. 27 (Normal carbon is $98.89 \%$ carbon- 12 and $1.11 \%$ carbon13.) In addition to the amorphous carbon powders, the simple sugar, d-Glucose, synthesized with in excess of $99 \%$ Carbon-13 making up the carbon atom component of its structure, is now available a modest cost ( $\$ 244 /$ gram $)$.

The Carbon-13 powder, with the Carbon-13 glucose sugar acting as a binder, might be hot pressed into a Carbon-13 sputtering target, for use in depositing a layer of Carbon-13 onto the end 
surface of a carbide pellet. Another possible binder for the production of a sputter target would be petroleum tar, which is widely used in the commercial production of carbon rods and carbon molds.

In fabricating carbide pellets, several precautions are in order. All the carbides will react with water to form a mixed gaseous product of methane, acetylene, and higher hydrocarbons. Therefore, any water vapor present, such as that in the starting materials, the glass of containers, the atmospheres of glove boxes, in dies, absorbed in crucible materials, or in relatively minute concentrations in whatever inert gas is chosen for the atmosphere in an annealing furnace, will degrade the product. A common failure mode is the formation of internal gas pockets of sufficient pressure to lead to disintegration of the desired geometric shape.

With this overview of the experimental proceedures to be followed, the following section presents a summary of the work that has been carried out.

\section{Laboratory Experiments Carried Out To Date}

Laboratory experiments carried out to date in the field of carbon-ion solid electrolytes have been such that they can be roughly classified into seven different categories:

\section{Formation of Pressed and Sintered Carbide Pellets.}

Approximately twenty attempts have been made to press and sinter cerium carbide, lanthanum carbide or aluminum carbide. The powders used have varied from irregular lumps of less than $2 \mathrm{~mm}$ to finely ground minus 325 mesh material which was ball milled in an inert atmosphere of argon inside a glove box. Binders of sucrose, glucose, benzene and Rohm \&Haas BE7-MEK (a methyl ethyl ketone solvent binder that totally evaporates at 400C) have been tried. Pressing has been under a 32 Ton capacity hydraulic press in hardened steel dies of 0.5 and 0.9 inch diameter. Dies have been bought commercially and built in the machine shop. An electric surround heater was purchased for the dies capable of $500 \mathrm{C}$, and pressing has been attempted cold, heated prior to pressing and heated after pressurizing. Pressures up to 10,000 atmospheres 
have been achieved, although failure of dies due to inelastic compressive strain of the piston has occurred more than once.

Despite all of the above described efforts, no successful pellets have been produced. All pellets have had such weak pre-sintered strength that they cracked during dismounting from the die, or while sintering in the argon atmosphere annealing furnace. It is the opinion of the investigator that the correct binder for the carbides has not been found.

However, as discussed the the following two sections, success has been achieved in forming solid carbide samples by means of casting ingots in an arc melt furnace. As discussed in Section Six, these are the materials that have been used for the x-ray evaluations carried out at the High Temperature Materials Laboratory at Oak Ridge National Laboratories.

\section{Formation of Melted Carbide Castings.}

Small circular castings of aluminum, lanthanum, cerium, zirconium, titanium, calcium and barium carbide have been successfully made in the arc melt furnace. Although operation of the arc melt furnace is somewhat of an art ( and an art that requires extensive practice), it has been found that by starting with very low argon gas pressures and low electric arc currents, castings can be made directly from fine powders of the carbides.

\section{Synthesis of Carbides Directly in the Arc Melt Furnace.}

After learning to make castings from the powders of cerium carbide and lanthanum carbide on a trial basis, it was decided to use the arc melt furnace to synthesize carbides directly from the elemental metal and carbon. These experiments were in the main successful. Aluminum carbide was successfully made, but later $\mathrm{x}$-ray diffraction revealed it to have substantial elemental aluminum and graphite as major contaminants. Cerium and lanthanum carbides have been made, but $\mathrm{X}$-ray diffraction revealed that the products were a mixture of the carbides $\mathrm{Ce}_{2} \mathrm{C}_{3} / \mathrm{CeC}_{2}$ and 
$\mathrm{La}_{2} \mathrm{C}_{3} / \mathrm{LaC}_{2}$, rather than solely the dicarbide that was desired. An experiment in which elemental lanthanum was reacted with $99.9 \%$ pure carbon-13 resulted in almost exactly the opposite of the desired result: A relatively pure $\mathrm{La}_{2} \mathrm{C}_{3}$ with almost no $\mathrm{LaC}_{2}$ was made and confirmed by $\mathrm{x}$-ray diffraction.

\section{Formation of Pressed and Sintered Carbon Sputter Targets.}

The standard one inch sputter target is a metal (usually copper, tungsten, tantalum or stainless steel) disk 1.00 inch in diameter and 0.250 inches thick that has a hollowed-out center cavity that is 0.900 inches in diameter and 0.125 . Into this cavity is inserted a material for sputtering. The material is bonded in place by soldering or shrink fitting. For the purposes of sputter coating a carbon layer onto carbides, a standard carbon one inch sputter target has been purchased from a commercial supplier. Attempts to have a commercial supplier build a carbon-13 isotope sputter target have been unsuccessful as of this date. Sixteen different suppliers have been contacted, but all have refused to even quote the job. Commercial carbon sputter targets are made by machining on a lathe a graphite rod down to the required dimensions. As no pre-made carbon rods of carbon-13 are available, suppliers have been reluctant to take on the "one-off" order.

Attempts have been made by the investigator to make a carbon- 13 sputter target by pressing and sintering. These attempts have been considered practice and have been made with natural carbon, rather than expensive carbon-13 itself. After receiving valuable advice and a proprietary tar binder from Great Lakes Carbon Incorporated in Morganton NC, a natural carbon material target was made using $20 \%$ by weight petroleum tar binder. This practice target appears had sufficient strength.

It should be noted that $80 \%$ of the natural carbon contained in the tar binder prior to sintering remains in the sputter target after sintering. Therefore $80 \%$ of $20 \%$ of the original weight of the target body will be natural carbon from the binder. If the sputter target is, for example, 0.8 
grams of $99.9 \%$ carbon- 13 isotope and 0.2 grams of tar binder, then the final weight will be $0.8+$ $0.2(80 \%)=.96$ grams. The final percent by weight of carbon-13 isotope will be 0.8 grams $(99.9 \%)+0.16$ grams $(1.11 \%) / 0.96$ grams $=83.4 \%$. As the natural percentage of carbon- 13 in earthly things containing carbon is $1.11 \%$, this represents an enrichment of $(83.4 / 1.11)=75$ to 1 .

To date approximately 5 attempts have been made to fabricate a sputter target with a carbon powder that analyses $99 \%$ Carbon-13. As of this date, targets can now be routinely produced up to the green pressed stage of fabrication. These green pressed targets are dense and have smooth outer surfaces, as a good target needs.

A major advance has been the addition of approximately $5 \%$ by weight carbon fibers to the carbon powder prior to pressing. These carbon fibers re-inforce the pressed material in a manner similar to the re-inforcement that steel "re-bar" adds to poured concrete. The carbon fibers are of natural carbon composition however. (98.9\% Carbon-12 and 1.1\% Carbon-13)

Another advance has been the use of acetone as a dispersant for the petroleum tar binder. The acetone is added to the mixture of carbon-13 powder, carbon fibers and petroleum tar after these three items have been weighed and mixed. The acetone is then allowed to disperse the tar evenly over the surface area of the carbon-13 powder and the fibers. The acetone is then removed by vacuum distillation prior to pressing. It has been found that complete removal of the acetone is crucial, as this volatile liquid will out-gas during sintering and fragment the pressed target.

\section{Differential Thermal Analysis Detection of Carbide Transition Temperatures.}

Differential Thermal Analysis has been attempted as a method of detecting the alpha to beta transformation temperature of cerium and lanthanum carbide in the temperature range of 1000 to 1500C. At these temperatures, the carbides are prone to quickly hydrolyze if any water vapor is present. Using an inert atmosphere of ultra-high-purity argon and water trapping filters, several runs appeared to show a transition temperature of approximately $1170 \mathrm{C}$. This transition 
temperature did not appear to be lowered or raised in a statistically significant manner when the carbides were doped at 8 mole $\%$ with $\mathrm{Ba}, \mathrm{Ca}$, Ti and $\mathrm{Zr}$ carbides, or with 10 mole $\% \mathrm{ZrN}$.

The peaks shown at the transition point in DTA were small, and did not always appear again (with the expected temperature change hysterisis) upon cooling. However, high temperature $\mathrm{x}$-ray diffraction later confirmed (see below) both that the transition temperature is in the range of $1100-1300 \mathrm{C}$, and that the doping of these carbides did not change the transition temperatures measurably. It may possible to use DTA to measure changes in transition temperature if:

1. Larger samples weights are used to lesson the effect of surface oxidation and to increase the magnitude of the transition energy peak to well above the resolution of the DTA machine's capability.

2. Optimum heating and cooling rates are found that are suited to the carbides.

\section{X-Ray Diffraction analysis of crystal structures and transition temperatures.}

The investigator was fortunate to have a proposal accepted by The High Temperature Materials Laboratory (HTML) at Oak Ridge National Laboratories to use their high temperature XRay Diffraction equipment to determine the crystal structure and transition temperatures of pure and doped cerium carbides and lanthanum carbides. Room temperature X-Ray Diffraction was also run on pure and doped aluminum carbides. Three weeks have been spent making these runs, and another week is planned in January of 1996. The results of these runs are ongoing and voluminous, but will briefly be summarized here.

$\mathrm{X}$-Ray Diffraction Patterns confirm that cerium dicarbide transforms to the fluorite prototype crystal structure in a very sluggish transition in the temperature range of $1350-1400 \mathrm{C}$. Upon cooling the cerium dicarbide, the phase transition will not occur at $1100 \mathrm{C}$ after a waiting period of four hours, but occurs within 30 minutes at 1050C. Figure 4 is a X-Ray peak spectra of cerium dicarbide showing its transformation at high temperature. 


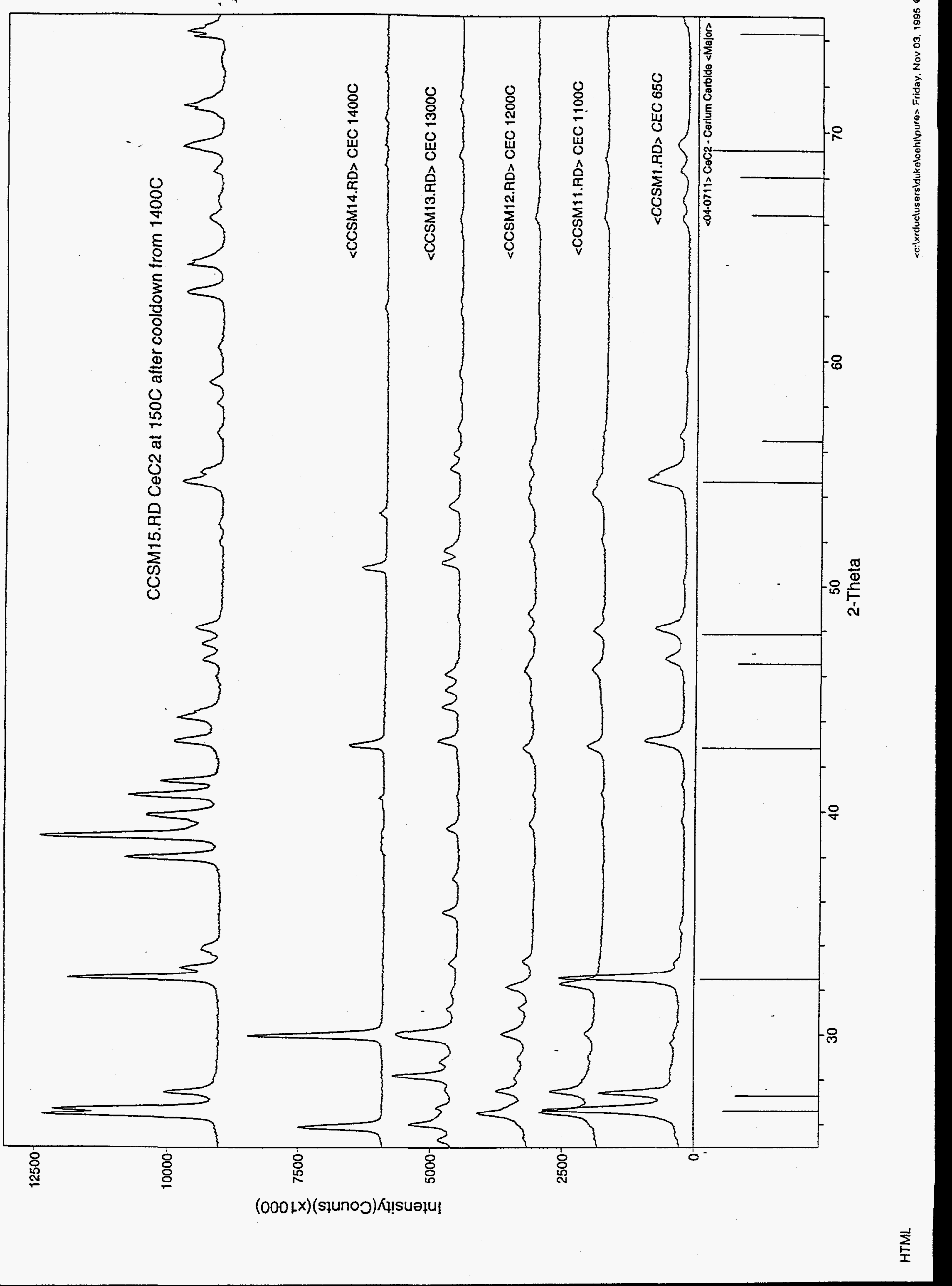




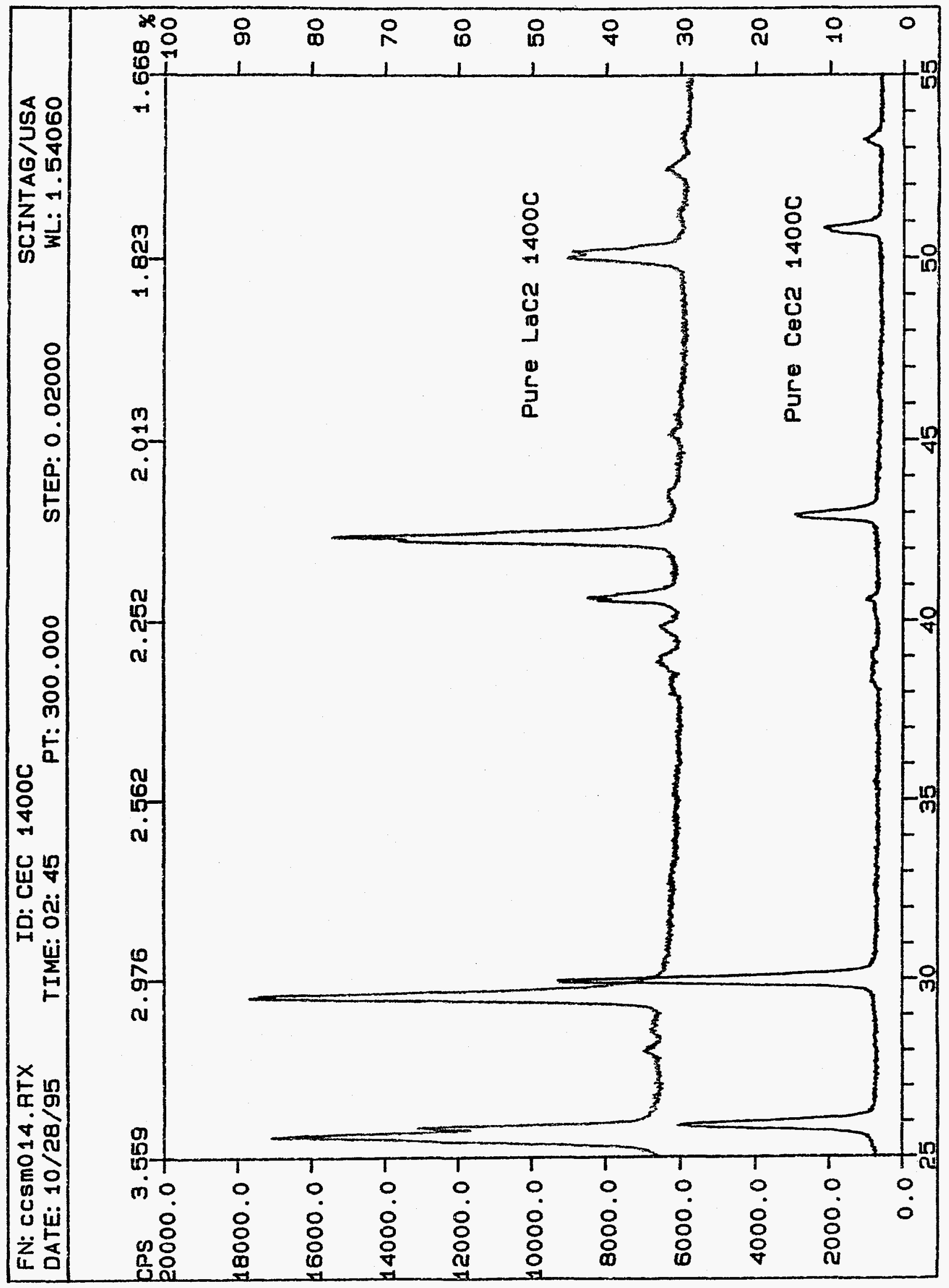




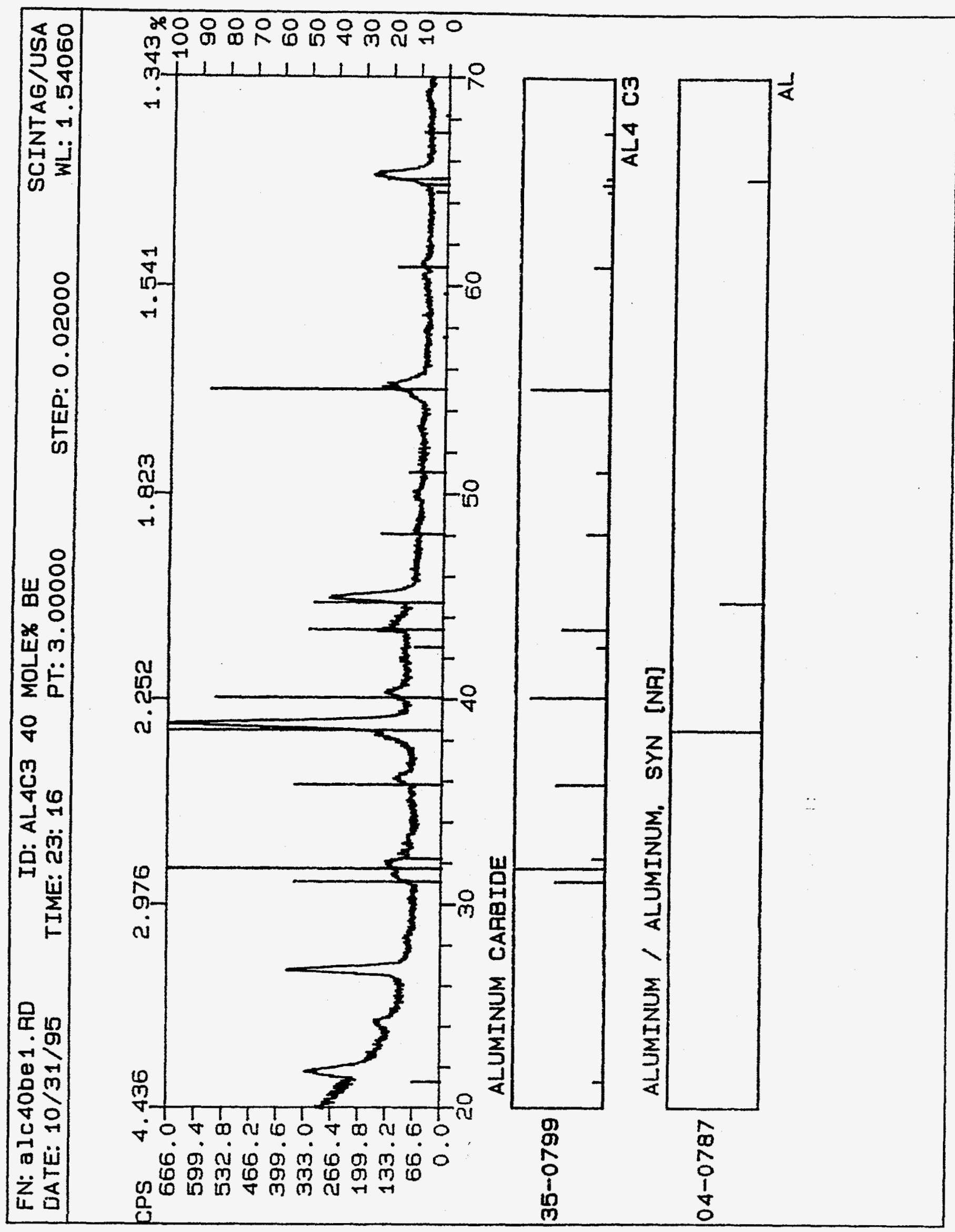




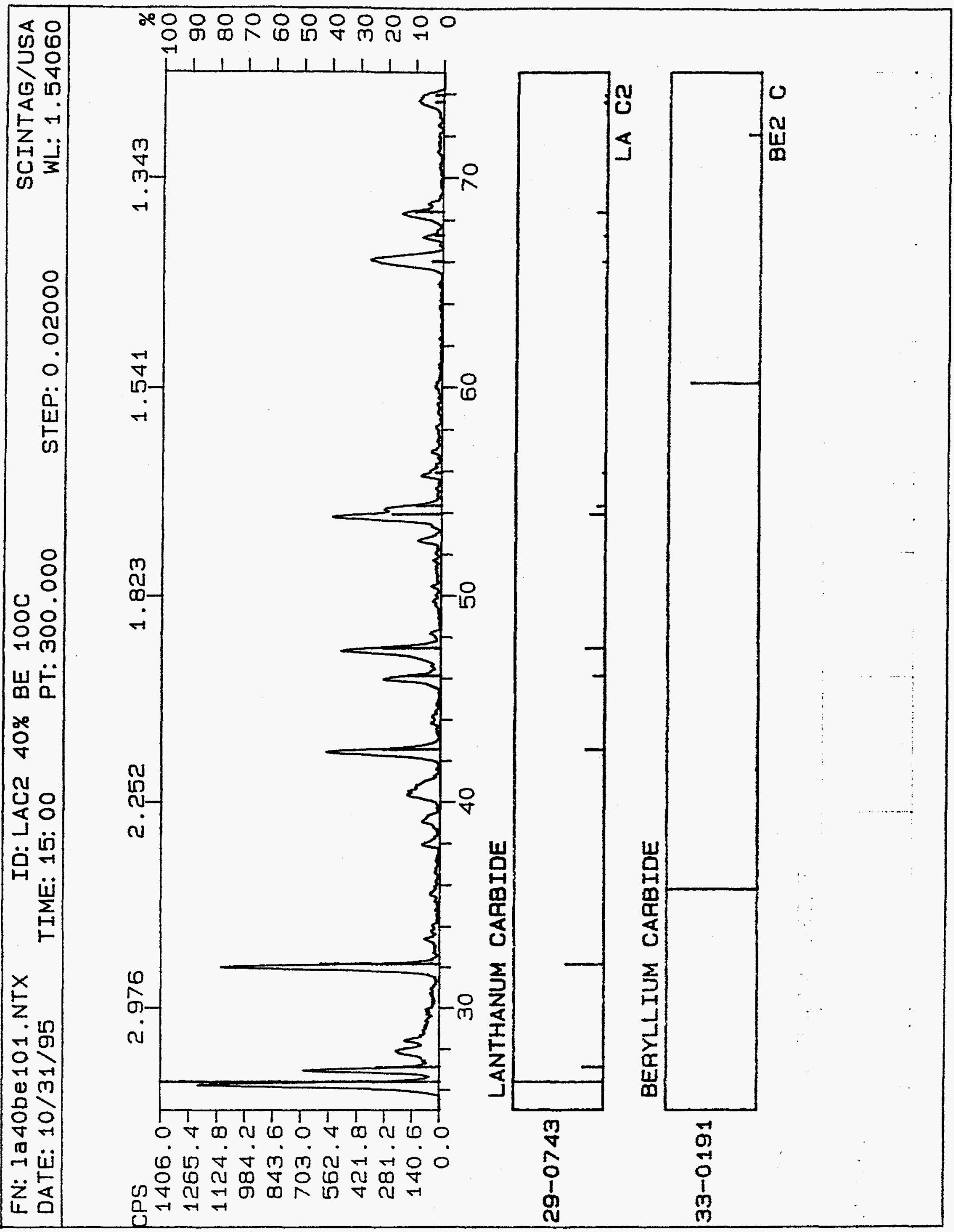


Lanthanum dicarbide transforms into a pseudo-fluorite structure above a transition in the temperature range of $1350-1400 \mathrm{C}$. The pseudo-fluorite pattern has each of the fluorite peaks split, indicating that the cubic symmetry is distorted into a symmetry that is slightly tetragonal. This may also indicate that the carbon-ions in $\mathrm{LaC}_{2}$ are double carbons. Figure 5 is a comparison of the $\mathrm{X}$ Ray peak spectra of lanthanum dicarbide and cerium dicarbide in their high temperature crystal structures. Notice the split peaks of lanthanum dicarbide.

The X-Ray Diffraction patterns of cerium and lanthanum dicarbides doped with $\mathrm{Ba}, \mathrm{Be}, \mathrm{Li}$, $\mathrm{Mg}$ and $\mathrm{Zr}$ indicate that these dopants are miscible in the dicarbide, except for $\mathrm{ZrC}$ where greater than 35 mole\% $\mathrm{ZrC}$ resulted in a pattern with peaks indicating that free $\mathrm{ZrC}$ is present as a second phase. The alpha crystal structure of the dicarbides (tetragonal $\mathrm{CaC}_{2}$ type) and the beta crystal structure of the dicarbide (fluorite $\mathrm{CaF}_{2}$ type) remained the same for all dopants and dopant amounts.

$\mathrm{X}$-Ray Diffraction carried out at Oak Ridge yielded interesting results concerning aluminum, lanthanum and beryllium carbides. Figures 6 and 7 are patterns of aluminum carbide and lanthanum carbide doped with 40 mole\% beryllium carbide respectively. Note that the beryllium appears to miscible in both. Aluminum carbide and lanthanum carbide doped with 5 - 25 mole\% beryllium carbide showed similar patterns. Lines for $\mathrm{Be}_{2} \mathrm{C}$ were either not found or so low that they were near noise level.

Dopant mole percentage levels were calculated from the stoichiometric amounts of elements added prior to casting in the arc melt furnace. It is recommended that the samples previously $\mathrm{X}$ Rayed, and all future samples, be analyzed by chemical methods in an independent commercial laboratory to ascertain their true elemental analysis. It cannot be assumed that a dopant added to the melted carbide ended up in the resultant casting, as the casting action in the arc melt furnace can at times be vigorous, sputtering and boiling.

\section{Secondary Ion Mass Spectroscopy analysis of carbon isotopes.}


The investigator was fortunate to receive from the Micro-Electronics Center of North Carolina (MCNC) a scholarship to be trained in the use of a Perkins-Elmer Model 1200 Secondary Ion Mass Spectrometer. This (SIMS) instrument has a resolution of approximately 1 part in 500 atomic mass-electrostatic charge units. At this level of resolution, the SIMS instrument should be easily capable of resolving the difference between a carbon-12 ion ( $12.00000 \mathrm{amu})$ and a carbon-13 ion (13.00335).

There is a potential problem of resolving the difference between the complex ion carbon-12 hydrogen-1 (13.007825 amu) and a singular carbon-13 ion (13.00335). The difference .004475 amu, is approximately one part in 200. $(1 / .004475=223)$ This is not expected to be a significant problem due to the following factors:

a. A carbon-12 hydrogen-1 ion will usually have a different charge on it than a carbon-13 ion.

b. Water reacts with carbides, forming the gas methane, which then leaves the solid. This makes the carbides somewhat "self-desiccating."

c. Moisture is necessary to form a $\mathrm{C} 12 \mathrm{H} 1$ ion, and the moisture level of the samples and SIMS vacuum chamber will be kept as low as possible.

Another potential problem in SIMS analysis is the surface of the carbide casting being analyzed. It would be beneficial to the accuracy of the SIMS results (and the associated depth profile of the sputtered crater in the sample) if the surface were initially smooth and flat. Irregular surfaces can be analyzed by SIMS more readily if the irregular surface is rotated during analysis.

Despite these potential problems, it is expected that the MCNC SIMS machine will be able to complete a depth and carbon-13 profile of the carbide casting. If problems do arise, more sophisticated SIMS analysis instruments are available for use at Oak Ridge National Laboratory and North Carolina State University. 


\section{Plan for Next Quarter (11th Quarter)}

In the upcoming 11th Quarter of this research project the following experimental procedures will be initiated:

1. Rare Earth Carbide ingots will be cast containing:

a. $50 \%$ by mole mixture of Cerium Dicarbide and Lutetium Dicarbide

b. $50 \%$ by mole mixture of Cerium Dicarbide and Erbium Dicarbide

c. $50 \%$ by mole mixture of Cerium Dicarbide and Ytterbium Dicarbide

These sample ingots will be made in the arc melt furnace and sub-divided so that each can be both $\mathrm{x}$-rayed to determine the crystal structure of the mixture, and chemically analysed to determine the actual elemental composition resulting after arc melting.

2.Cast carbide ingots containing Cerium Dicarbide, Beryllium Carbide and Aluminum Carbide will be made in which the amounts of the three carbides will be varied in $15 \%$ by mole increments. The following combinations will be made in the arc-melt furnace:
a. 15,30 mole $\% \mathrm{Be}_{2} \mathrm{C}$ in $\mathrm{CeC}_{2}$.
b. 15,30 mole $\% \mathrm{CeC}_{2}$ in $\mathrm{Be}_{2} \mathrm{C}$.
c. 15,30 mole $\% \mathrm{Al}_{4} \mathrm{C} 3$ in $\mathrm{CeC}_{2}$
d. 15,30 mole $\% \mathrm{CeC}_{2}$ in $\mathrm{Al}_{4} \mathrm{C}_{3}$
e. 15,30 mole $\% \mathrm{Be}_{2} \mathrm{C}$ in $\mathrm{Al}_{4} \mathrm{C}_{3}$
f. 15,30 mole $\% \mathrm{Al}_{4} \mathrm{C} 3$ in $\mathrm{Be}_{2} \mathrm{C}$.

3. After casting these 12 samples will be split into four sub-samples each.

4. One sub-sample will be sent off for chemical analysis to confirm elemental content. 
5. The second sub-sample will be analyzed by high temperature $\mathrm{x}$-ray diffraction at the facilities of the High Temperature Materials Laboratory at Oak Ridge.

6. The third sub-sample will be re-melted to form at circular pellet suitable for sputter coating with a carbon layer that will consist of 80 mole \% carbon-13 isotope and 20 mole \% carbon- 12 isotope. These sputter coated sub-samples will be annealed at $1500 \mathrm{C}$ under argon.

7. The third sub-samples will then be analyzed for Carbon- 13 content versus depth by Secondary Ion Mass Spectroscopy at the facilities of the North Carolina Microelectronics Center.

8. The fourth sub-sample will be remelted and analysed similar to that of the third sub-sample described in steps 6-7 above, except that instead of sputter coating the circular pellet, a slurry of carbon powder and acetone will be deposited onto the top surface of the the pellet. The liquid acetone will then be removed by air drying, followed by vacuum distillation to create a carbon layer. The fourth sub-sample will then be annealled and analysed by SIMS.

It is anticipated that successful completion of the above procedures will require additional time and effort beyond the 12th Quarter of this research project. Therefore, the investigators intend to apply for a no-cost extention of the project to add two more quarters. Despite this request, all efforts will be made to complete the research in the time presently allowed. 


\section{REFERENCES}

1. D.K Fleming and K.A. Atabay, Modern Power Systems, August, $1990, \mathrm{v} 10$, No.8.

2. Metals and Materials Magazine,"Fuel Cells: Probably the Best Generators in the World", Vol.8,No.11,Nov.1992.

3. A. Conway, Modern Power Systems, Oct.,1990,No.10.

4. A.J. Appleby and F.R. Foulkes, Fuel Cell Handbook. Van Nostrand Reinhold, 1989.

5. Appleby, op cit, p16-21.

6. Ilan Riess, "The Possible Use of Mixed Ionic Electronic Conductors Instead of Electrolytes in Fuel Cells," Solid State Ionics, 1992, V.52, p127-134.

7. A.F. Wells, Structual Inorganic Chemistry, Clarendon Press, 1984, p947-.953

8. Wells, op cit. p948.

9. Journal of the American Chemical Society,1943,V.65, p602,1482.

10. Inorganic Chemistry, 1962,V.1,p.345,683.

11. T.M.Gur,and R.A.Huggins, "Direct Electrochemical Conversion of Carbon to Electrical Energy in a High Temperature Fuel Cell", J.Electrochem Soc., Vol 139, No.10, Oct.1992.

12. T.B. Massalski, Binary Alloy Phase Diagrams. Second Ed., Vol. 1-3, ASM International, 1990,p130-899.

13. H. Haschke and H. Nowotny, "New Perovskite Carbides", Monatsh. Chem..1967,v98,n2.

14. R.W.G. Wyckoff,ed., Crystal Structures, Second Ed.. Interscience Publishers, 1964.

15. Enel Corp.,"Italian Power Industry",Power Magazine,Vol.136,No. 12,Dec.1992.

16. Electric Power Research Institute, personal communication to F.H. Cocks, 1980.

17. Appleby, op cit.

18. B.C.H. Steele, "High Temperature Fuel Cellsw Incorporating Ceramic Electrolytes," in Electrochemistry and Clean Energy, J.A.G. Drake, ed, Royal Society of Chemistry, 1994.

19 J.W. Locher and F.H. Cocks, J. of Materials Science, $\mathrm{v} 15,1980, \mathrm{p} 2520-2522$.

20. Locher, op cit.

21. Massalski, op cit,

22 I.R.Loe, I.J. McColm, and T.A. Quigley, "Cubic to Tetragonal Transformations in

Dicarbides," J. of Less Common Metals, 46 (1976) 217-227.

23. Loe, op cit, p227.

24. Sammells, A.F., Cook, R.L., MacDuff, RC, "Perovskite Solid Electrolytes for Intermediate Temperature solid Oxide Fuel Cells," J. Electrochemical Society, Oct 1990, pps 3309-3310.

25. F.H. Cocks and H. LaViers, "Novel Carbon-Ion Fuel Cells, DOE Proposal to the University Coal Research Program DE-FG22-93PC93219, 1992.

26. Paul Shewman, Diffusion in Solids, 2nd Ed, Minerals, Metals and Materials Society, $1989, \mathrm{p} 154$

27. Aldrich Chemical Co., 1994-95 Catalog, p288.

28. Lesley Smart and Elaine Moore, Solid State Chemistry, Chapman and Hall, 1992,p26. 